\title{
ESTUDO DA EXTRAÇÃO DE ÓLEO VEGETAL COM SOLVENTE EM LEITO FIXO EMPREGANDO ENERGIA SOLAR
}

\author{
M. B. M. RIBEIRO ${ }^{1}$, L. R. C. SILVA $^{2}$ e K. G. SANTOS $^{1}$ \\ ${ }^{1}$ Universidade Federal do Triângulo Mineiro, Departamento de Engenharia Química \\ ${ }^{2}$ Universidade Federal do Triângulo Mineiro, Departamento de Química \\ E-mail para contato: marinabmaluf@gmail.com
}

RESUMO - O uso da energia solar como fonte de energia renovável tem se tornado uma boa alternativa sustentável nos dias de hoje e seu emprego tem crescido. Os concentradores solares são utilizados quando se deseja obter grandes taxas de energia térmica, e são constituídos de uma superfície refletora de radiação solar que capta a luz incidente e concentra em uma região focal. $\mathrm{O}$ trabalho teve como objetivo a extração de um óleo de amendoim de boa qualidade através do processo de lixiviação em leito fixo utilizando energia solar para aquecer o solvente. Foram feitos testes de aquecimento com água em diversas vazões para verificar a eficiência térmica do concentrador cilindro-parabólico. Os testes de extração foram realizados com uma amostra de $120 \mathrm{~g}$ de amendoim triturado e com 2 horas de duração. O rendimento da extração de óleo pode ser calculado comparando a massa da torta seca com o teor de óleo obtido pelo método Soxhlet. Os testes com água mostraram que a vazão que atinge uma maior temperatura de saída no leito é a de $15 \mathrm{~mL} / \mathrm{min}$, pois ela demora mais tempo para o percorrer. Os experimentos de extração foram feitos com as vazões de 15,25 e $35 \mathrm{~mL} / \mathrm{min}$. A vazão que foi considerada ideal para o processo foi a de $25 \mathrm{~mL} / \mathrm{min}$, pois teve o melhor rendimento de extração do óleo, com $73,04 \%$, e atingiu temperaturas na casa dos $60^{\circ} \mathrm{C}$, que favorece a solubilidade do óleo no álcool. Foi possível extrair óleo de amendoim de maneira sustentável e com baixo investimento.

\section{INTRODUÇÃO}

O uso de energias renováveis vem crescendo no mundo atual. O emprego desse tipo de energia, segundo Ho e Ito (2007), além de reduzir os impactos negativos resultantes da queima de combustíveis fósseis, permite uma melhoria na qualidade de vida, diminuindo a dependência econômica dos países em desenvolvimento. Nesse contexto, a energia solar destaca-se por ser uma fonte de energia não poluente, pura, abundante e disponível em qualquer lugar do planeta Terra.

Uma forma de utilizar o sol como fonte inesgotável de energia é através dos coletores solares. O uso destes sistemas se expandiu muito rapidamente, por serem equipamentos de baixo custo e fácil construção. Estes podem ser utilizados em várias aplicações na indústria, em residências e na agricultura (Santos e Nascimento Filho, 2002). 
Em situações onde se desejam obter grandes taxas de energia térmica e temperaturas mais elevadas, podem ser utilizados os concentradores solares. Seu funcionamento é baseado nas leis de reflexão e refração de espelhos ou lentes, os quais direcionam a luz para um ponto focal (URIAS, 2014). São de fácil construção e de baixo custo, sendo constituídos basicamente de uma superfície refletora-concentradora da radiação solar direta, que tem a finalidade de captar a energia solar incidente e concentrá-la em uma região onde estará localizado o corpo absorvedor.

O presente trabalho em tenciona realizar a extração de óleo de amendoim através de solvente. A extração de óleo por solvente é um processo de transferência de constituintes solúveis (o óleo) de um material inerte (a matriz graxa) para um solvente com o qual a matriz se encontra em contato. Segundo Brum et al. (2009) os processos que ocorrem são apenas físicos, pois o óleo transferido para o solvente é recuperado sem nenhuma reação química. De acordo com Tomazin Junior (2008) o processamento para obtenção do óleo por solvente se inicia com o preparo do grão, a fim de facilitar a penetração do líquido, em que este é submetido a redução de tamanho, de espessura e aquecimento. A temperatura do processo deve ser próxima ao ponto de ebulição do solvente, o que reduz a viscosidade do óleo e aumenta sua solubilidade no solvente, garantindo assim uma melhor eficiência de extração (Gandhi et al., 2003).

Um dos solventes mais utilizados comercialmente para extração é o etanol. O etanol é um solvente polar, biodegradável, não toxico e possui grande potencial para extração de óleo (Tomazin Junior, 2008). Este se destaca por ser uma boa alternativa para substituição do hexano, composto derivado do petróleo e tóxico, como solvente de extração sem perdas de rendimento. A baixa solubilidade do etanol a temperatura ambiente possibilita a separação das fases óleo e solvente sem a necessidade de evaporação, destilação. Apenas por um simples período de resfriamento, obtém-se duas fases distintas, uma micela rica em óleo e outra micela rica em álcool.

Assim, o concentrador solar cilindro-parabólico será responsável por aquecer de forma direta o solvente, o qual será empregado na obtenção de óleo pelo processo de lixiviação das sementes de amendoim. A extração ocorrerá de maneira contínua e a variável do processo estudada será a vazão de entrada de solvente. Com isso, pretende-se determinar a melhor vazão de alimentação do solvente álcool. Além disso, pretende-se calcular a eficiência de extração do equipamento construído através de uma comparação com o rendimento de óleo extraído por este e pelo método convencional (extrator tipo Soxhlet).

\section{METODOLOGIA}

\subsection{Estrutura do concentrador parabólico}

A superfície tipo calha foi feita de zinco onde seria feita a parte refletora do concentrador, que é composta por retalhos de espelhos inutilizados que foram doados por uma vidraçaria localizada em Uberaba-MG. Estes foram cortados em tiras de tamanhos iguais (53 x $5 \mathrm{~cm}$ ) de modo a acompanhar a curvatura da calha. As tiras de espelho foram coladas com cola a base de silicone sob a chapa de zinco. O leito absorvedor utilizado foi um tubo de cobre de diâmetro de $3 \mathrm{~cm}$ e $160 \mathrm{~cm}$ de comprimento. $\mathrm{O}$ tubo foi revestido com tinta preta fosca de modo a aumentar a absorção dos raios refletidos. $\mathrm{O}$ concentrador possui um eixo que permite 
ajustar sua inclinação de acordo com a mudança da posição do sol. O esquema da unidade experimental e a imagem real do projeto podem ser observados na Figura 1 a seguir.

Figura 1 - Unidade experimental do concentrador solar cilindro-parabólico em esquema e imagem real

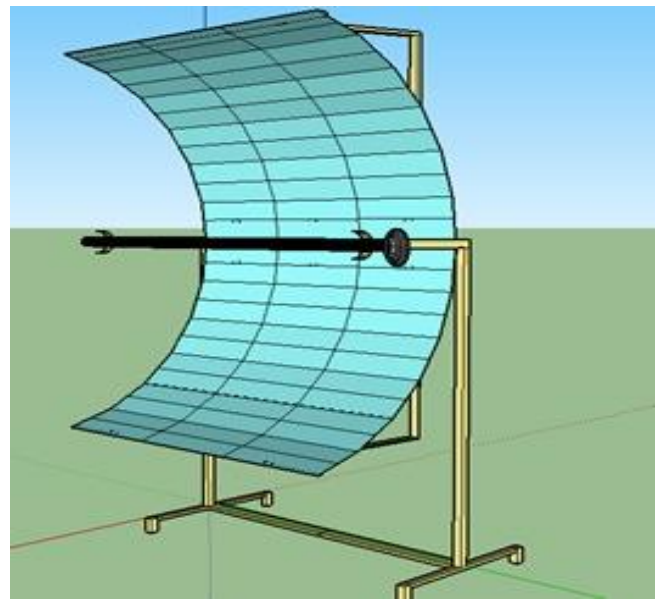

(a)

Fonte: desenho da autora

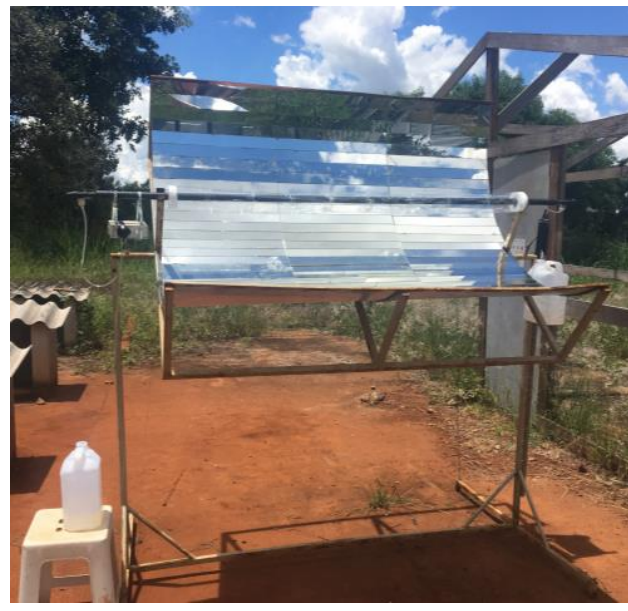

(b)

Fonte: fotos tiradas pela autora

\subsection{Processo de extração}

Os testes de extração foram realizados na cidade de Uberaba, localizada na região do Triângulo Mineiro, no estado de Minas Gerais, a qual possui uma radiação solar média de $5.800 \mathrm{Wh} / \mathrm{m}^{2}$ e um nível de insolação médio diário de 7 horas (ANEEL, 2005). A temperatura de operação é definida pela vazão de alimentação do solvente e pela quantidade de radiação solar durante o experimento. Assim, todos os testes foram realizados durante o período entre 10:00 e 15:00 para dias ensolarados.

Primeiramente, o leito absorvedor foi preenchido com as partículas, sendo a massa de amostra constante e igual a $120 \mathrm{~g}$ de amendoim triturado. Após isso, o solvente empregado, álcool etílico (96\%), foi bombeado com o uso de uma bomba dosadora peristáltica à baixas vazões para dentro do tubo absorvedor que continha as partículas. Cada teste teve duração média de duas horas. A cada meia hora o foco do concentrador foi regulado, rotacionando-o em seu eixo horizontal de acordo com o movimento do sol, para a direção de maior incidência dos raios solares.

\subsection{Variáveis analisadas}

Após a adaptação da unidade experimental, foram feitos testes de aquecimento com água para analisar a eficiência térmica do concentrador e calcular as possíveis vazões de alimentação de solvente para o processo de extração. As vazões de solvente estudadas foram 15,25 e $35 \mathrm{~mL} / \mathrm{min}$. 
Com as possíveis vazões estabelecidas para o processo, deu-se início aos testes de extração com solvente. Ao final de cada experimento, a massa de torta era pesada e seca, a fim de determinar a massa de torta seca e assim, calcular a massa removida no processo de lixiviação. O óleo obtido foi separado por separação gravitacional, após manter a mistura óleo/solvente sob refrigeração. Em seguida, foi calculado o rendimento de extração em relação ao método convencional.

\section{RESULTADOS E DISCUSSÃO}

As curvas de aquecimento obtidas nos testes realizados com água no concentrador são mostradas nas Figuras de 2 a 4. Os testes foram feitos com vazões de alimentação de 15, 25 e $35 \mathrm{~mL} / \mathrm{min}$, a fim de definir as vazões a serem estudadas nos testes de extração com solvente. Como pode ser observado nos gráficos, o teste que atingiu a maior temperatura foi com a vazão de $15 \mathrm{~mL} / \mathrm{min}$, que chegou a uma temperatura de $85,7^{\circ} \mathrm{C}$. Com uma vazão de alimentação menor, a água demora mais a percorrer o leito, logo, é possível atingir uma temperatura maior até chegar à saída.

Figura 2 - Curva de aquecimento com vazão de 15 Figura 3 - Curva de aquecimento com vazão de 25 $\mathrm{mL} / \mathrm{min}$ no concentrador $\mathrm{mL} / \mathrm{min}$ no concentrador
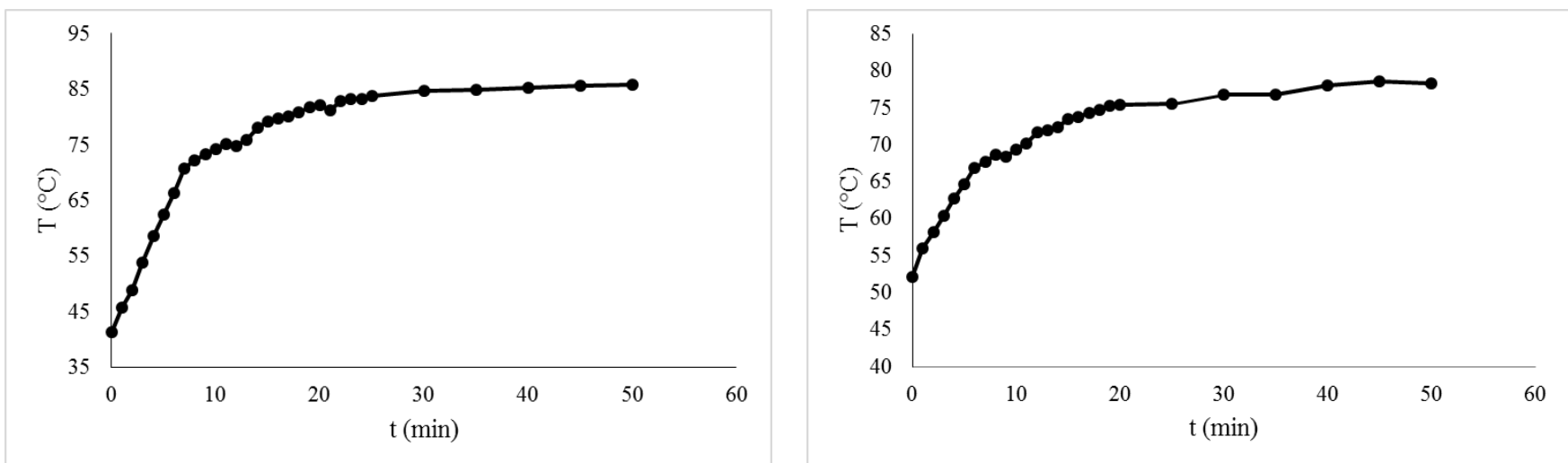

Figura 4 - Curva de aquecimento com vazão de $35 \mathrm{~mL} / \mathrm{min}$ no concentrador

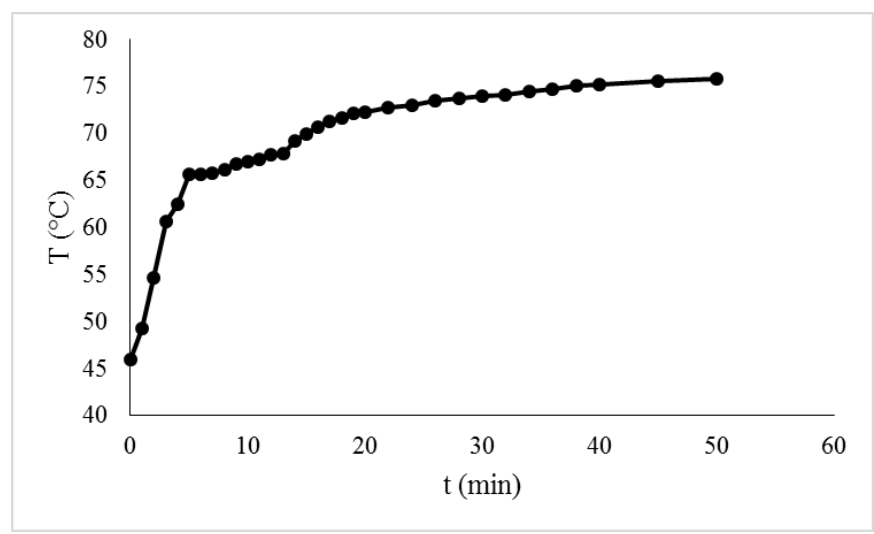


Assim, foram realizados os experimentos de extração com as vazões de 15,25 e 35 $\mathrm{mL} / \mathrm{min}$ e com duração de 2 horas. O óleo foi separado do álcool para posterior estudo de suas características. A torta remanescente foi levada para estufa a $100^{\circ} \mathrm{C}$ por 24 horas, e então foi pesada para calcular a massa de óleo extraída. O rendimento de cada experimento pode ser calculado comparando a massa removida na extração com o teor de óleo teórico presente no amendoim obtido pelo método convencional de Soxhlet. Os rendimentos obtidos para cada experimento estão dispostos na Tabela 1 a seguir.

Tabela 1 - Dados dos rendimentos obtidos nas extrações

\begin{tabular}{|c|c|c|}
\hline Concentrador & Vazão (mL/min) & Rendimento (\%) \\
\hline \multirow{3}{*}{ Cilindro-parabólico } & 15 & 66,21 \\
\cline { 2 - 3 } & 25 & 73,04 \\
\cline { 2 - 3 } & 35 & 47,39 \\
\hline
\end{tabular}

No processo de extração por solvente, a vazão de alimentação é uma das variáveis mais importantes a ser manipulada para que se atinja a condição ideal de operação. $\mathrm{O}$ aumento da vazão aumenta o rendimento até certo ponto, pois aumenta a velocidade relativa entre a partícula e o fluido, aumentando, assim, os coeficientes convectivos de transferência de massa. Porém, o aumento da vazão diminui o tempo de contato do fluido com a partícula, e também, no caso de extração com alimentação contínua em leito fixo, diminui o tempo em que o fluido percorre o leito, tendo, assim, uma temperatura de operação não tão alta, o que não favorece a solubilidade do óleo no solvente.

Dessa forma, a vazão que obteve um melhor rendimento foi a vazão intermediária estudada, de $25 \mathrm{~mL} / \mathrm{min}$, pois ela garante uma boa velocidade relativa e um bom tempo de contato fluido-partícula, e também atinge uma boa temperatura de operação, em que favorece a solubilidade do óleo no álcool. Com essa vazão, obteve-se uma temperatura de operação por volta de $63^{\circ} \mathrm{C}$ para o cilindro-parabólico.

\section{CONCLUSÃO}

A utilização do concentrador solar apresentou-se como uma boa alternativa para a extração de óleos vegetais empregando a energia solar, uma vez que atingiu eficiência de extração de até $73 \%$. Dessa forma, foi possível extrair óleo de amendoim de boa qualidade de maneira sustentável e utilizando recursos de baixo custo.

A vazão de operação que proporcionou um melhor rendimento para o processo foi a de $25 \mathrm{~mL} / \mathrm{min}$, que garante uma boa velocidade relativa entre o fluido e a partícula, ajudando na transferência de massa entre eles, e também opera em uma temperatura que favorece a solubilidade do óleo no álcool. Sendo assim, essa é a vazão ideal para o processo de extração com alimentação contínua em leito fixo, atingindo um rendimento de 73,04\% no concentrador solar cilindro-parabólico.

Uma das maiores vantagens do uso do concentrador solar para extração de óleos vegetais em comparação ao método convencional, é que este último exige uma grande carga de energia elétrica para operar, o que não acontece com o concentrador, pois a única energia 
elétrica necessária no sistema é destinada a bomba peristáltica, e essa, por sua vez, necessita de pouca energia.

Assim, a única desvantagem da operação de extração no concentrador solar é a necessidade de dias de operação com alta incisão de raios solares e baixa nebulosidade, assim como qualquer processo que utilize energia solar. Porém, como o custo energético desse processo é baixo, o equipamento utilizado neste trabalho apresenta alto potencial de aplicação, principalmente em pequenas comunidades, uma vez que é de fácil construção e operação, além de ser de baixo custo.

Um destaque importante para a extração de óleos vegetais, é que esses óleos apresentam-se como uma alternativa de renda extra, principalmente em lugares carentes e remotos, devido à alta concentração de óleo encontrada nas sementes de amendoim e da possibilidade de extração por técnicas sustentáveis, de baixo custo e fácil manuseio.

\section{REFERÊNCIAS}

ANEEL - Agência Nacional de Energia Solar (Brasil). Energia Solar. Disponível em: <http://www.aneel.gov.br/aplicacoes/atlas/pdf/03-Energia_Solar(3).pdf> Acesso em: 25 jan 2017.

BRUM, Aelson Aloir Santana; ARRUDA, Lia Ferraz de; REGITANO-D'ARCE, Marisa Aparecida Bismara. Métodos de extração e qualidade da fração lipídica de matériasprimas de origem vegetal e animal. Química Nova, São Paulo, v. 32, n. 4, p.849-854, 2009.

GANDHI, A. P., et al. Studies on alternative solvents for the extraction of oil-I soybean. International journal of food science \& technology, Oxford, v.38, p.369-375, 2003.

HO, Denny Anderson; ITO, Eric Ayao. Projeto e Construção de Aquecedor Solar com Concentrador. 2007. 102 f. Trabalho de Conclusão de Curso (Graduação em Engenharia Mecânica) - Escola Politécnica da Universidade de São Paulo, São Paulo, 2007.

SANTOS, Sebastião Amílcar de Figueiredo; NASCIMENTO FILHO, Jair. Coletores solares: materiais disponíveis no meio rural. In: Encontro de Energia no Meio Rural, 4., 2002, Campinas.

TOMAZIN JUNIOR, Celso. Extração de óleo de soja com etanol e transesterificação etílica na miscela. 2008. 64 f. Dissertação (Mestrado em Ciências) - Centro de Energia Nuclear na Agricultura, Piracicaba, 2008.

URIAS, Patrícia Moisés. Concentrador Solar Biangular de Doze Lados: método alternativo para extração de óleo a partir de semente de pinhão manso. 2014. $36 \mathrm{f}$. Trabalho de Conclusão de Curso (Graduação em Engenharia Química) - Departamento de Engenharia Química. Universidade Federal do Triângulo Mineiro, Uberaba, 2014.

\section{AGRADECIMENTOS}

Agradecimento à FAPEMIG pela bolsa BIC/FAPEMIG, ao PPGMQMG e à UFTM. 